\title{
Phenotypic characterisation and infection of ovine microglial cells with Maedi-Visna Virus
}

\author{
Bahram Ebrahimi $^{1}$, Timothy E Allsopp ${ }^{1,2}$, John K Fazakerley ${ }^{1}$ and Gordon D Harkiss ${ }^{*, 1}$ \\ ${ }^{1}$ Department of Veterinary Pathology, University of Edinburgh, Edinburgh, EH9 1QH, UK
}

\begin{abstract}
Maedi-Visna Virus (MVV) infection of the central nervous system (CNS) results in pathological changes, the mechanisms of which are poorly understood. MVV preferentially infects cell of the monocyte/macrophage lineage in vivo. The neuroparenchymal microglial cells are the resident tissue macrophages in the CNS and therefore likely targets for MVV infection. However, no information is currently available on the susceptibility of these cells to MVV infection or their contribution to neuropathological changes as a result of MVV infection. Highly enriched primary ovine microglial cell cultures were set up from brain tissues of lambs. These cells were amoeboid or bipolar with spikes, a morphology consistent with microglial cells of other species, and stained positive for CD1, CD11a, CD11c, CD14, MHC-class I, MHC-class II, and $\beta$-N-acetyl galactose, but not with markers of astrocytes or oligodendrocytes. These sheep microglial cells were permissive for MVV infection. Productive MVV infection resulted in selective transcriptional upregulation of the pro-inflammatory cytokines $\mathrm{TNF} \alpha$ and IL-6. In contrast, there was no change in levels of transcripts for TGF $\beta 1$, IL-1 $\beta$, GM-CSF, IL-10, or IL-12. These data provide the first evidence that ovine microglial cells can support productive infection with MVV, and that this leads to a selective upregulation of proinflammatory cytokines. These may contribute to visna neuropathology. Journal of NeuroVirology (2000) 6, 320-328.
\end{abstract}

Keywords: CNS; cytokine; cell culture; lentivirus

\section{Introduction}

The lentivirus subfamily of Retroviridae includes the human, simian, feline, and bovine immunodeficiency viruses (HIV, SIV, FIV, BIV respectively), equine infectious anaemia virus (EIAV), caprine arthritis-encephalitis-virus (CAEV) and maedi-visna virus (MVV). One outcome of lentiviral infection can be central nervous system (CNS) disease (reviewed by Georgsson, 1994).

The CNS disease in sheep naturally infected with MVV presents a sub-acute encephalomyelitis with an insidious outset which develops into rapidly deteriorating hind leg paralysis (reviewed by Palsson et al, 1974). A common feature of the CNS pathology which can be reproduced by intracerebral inoculation of MVV is extensive perivascular cuffing and lymphocytic infiltration of the neuroparenchyma. Although no correlation has been

\footnotetext{
*Correspondence: GD Harkiss

${ }^{2}$ Current address: Fujisawa Institute of Neuroscience, University of Edinburgh, Edinburgh, EH8 9JZ, UK

Received 3 June 1999; revised 25 October 1999; accepted 13 March 2000
}

established between the extent of the inflammatory response in the CNS and the degree of clinical disease, early CNS disease is believed to be immune mediated (Nathanson et al, 1976; Torsteinsdottir et al, 1992; 1994). MVV infection of the CNS results in lesions of demyelination similar to those observed in multiple sclerosis in humans (Palsson, 1974). In both MVV and HIV-1, encephalitis may be an early feature. However, the chronic stages of HIV-1 infection include multinucleated giant cells and white matter pallor (Budka, 1989), whereas multinucleated giant cells are a rare occurrence in MVV and there is no report of white matter pallor associated with visna (reviewed by Georgsson, 1994).

Intracerebral infection experiments with MVV have established an association between extent of pathological changes and frequency of virus isolation from affected tissues (Petursson et al, 1976). However, an anomaly exists between the number of virus antigen-positive cells in the brain parenchyma and the extent of the neuropathology (Georgsson et $a l, 1989)$. This disparity is not confined to ruminant 
lentiviruses; similar observations have also been made in HIV-1 and SIV encephalopathies (Gabuzda et al, 1986; Wiley et al, 1986; Kure et al, 1991; Brinkman et al, 1993; Nuovo and Alfieri, 1996).

Increased intrathecal expression of pro-inflammatory cytokines has been associated with neuropathological changes in primate lentivirus infections (Genis et al, 1992; Koka et al, 1995; Lane et al, 1996). Similarly, MVV infection has been shown to induce expression of $\mathrm{TNF} \alpha$ within brain tissues (Craig et al, 1997). Furthermore, lentiviralencoded components, such as the MVV and HIV-1 transactivator of transcription (tat) can induce the expression of TNF $\alpha$, IL-6, and IL- $1 \beta$ in rodent brains (Philippon et al, 1994). The apparent discordance between the number of virus antigen-positive cells and the severity of the neuropathology may, at least in part, be explained by cytokines and be independent of direct virus infection (reviewed by Gendelman et al, 1994).

Microglial infections by HIV-1, SIV, FIV, and CAEV have been demonstrated (Gabuzda et al, 1986; Wiley et al, 1986; Lackner et al, 1991; Dow et al, 1990, Baszler et al, 1994). However, MVV infection of ovine microglial cells has not been conclusively established, and consequently studies on the effects of MVV infection of microglial cells are lacking. The aims of this work were to establish and characterise cultures of ovine microglial cells, to determine whether these could be infected by MVV and to investigate any subsequent changes in the expression of cytokine transcripts.

We report here the characterisation of highly enriched ovine microglial cell cultures, and their infection by MVV. MVV infection of these cells resulted in a selectively increased transcription of microglial-derived TNF $\alpha$ and IL-6. The implications of these findings for visna neuropathology are discussed.

\section{Results}

Morphological features of cultured cells

Ovine microglial cell cultures have not previously been established and characterised. To establish cultures of cells with a morphology consistent with that observed in cultured microglia from other species, a number of tissue culture procedures were tried. The technique eventually used is detailed in the Materials and methods section.

High density primary glial cultures were prepared from lamb brains. Floating non-adherent cells were removed and brief plating of these cells resulted in selection and enrichment of putative ovine microglial cells.

Twenty four hours after enrichment, and on the basis of morphology, the vast majority ( $>98 \%$ ) of cells could broadly be divided into either amoeboid or process bearing (Figure 1). The amoeboid cells had membrane spikes evenly distributed around the cell body. The process bearing cells were often bipolar and had asymmetric membrane spikes which were focally distributed on the tip of the long processes and on the main cell body (Figure 1). These morphological features are entirely consistent with those described for both rodent and human cultured microglial cells (Giulian et al, 1995).

These putative microglial cultures were characterised by immunostaining with a panel of cell markers. The greater majority of cells stained positive for CD1, CD14, MHC-class I, CD11a, CD11c, and $\beta$-NacGal (Figures 2 and 3 and the
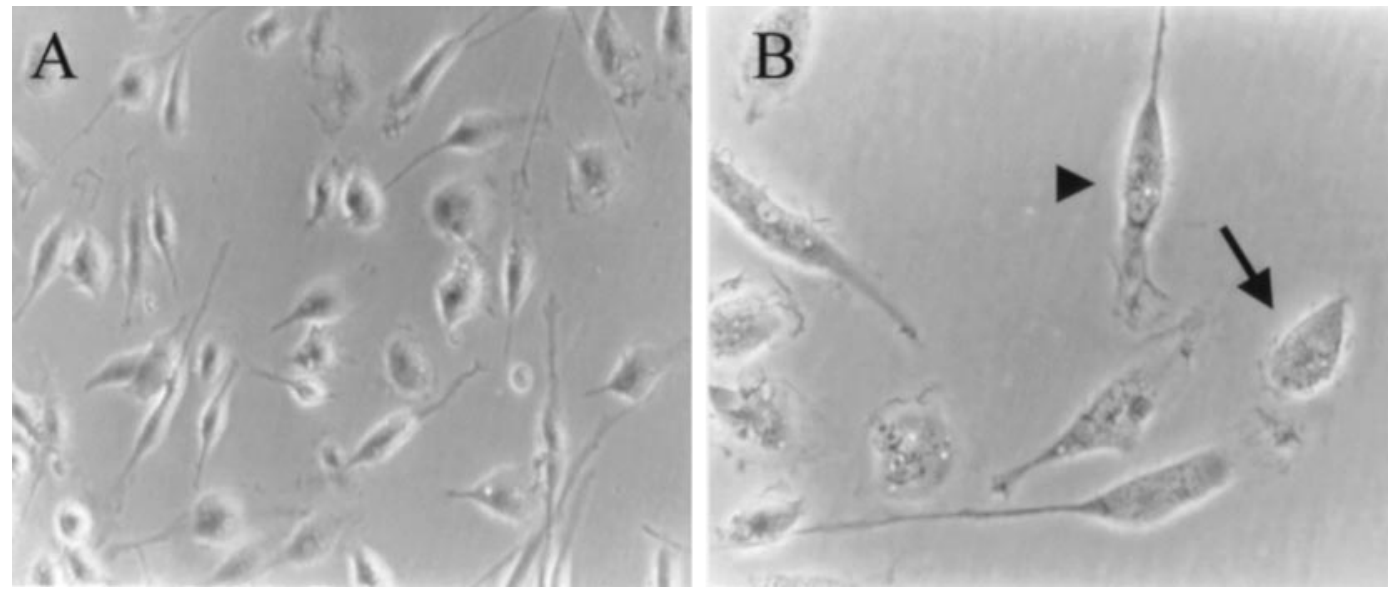

Figure 1 Morphological characterisation of ovine microglial cultures. Glial cells were obtained from brains of new born lambs and enriched for microglial cells by adherence. Twenty-four hours post-enrichment, these glial cells showed both flat and bipolar morphologies. Both (A) and (B) show phase contrast photographs of live cells. (A) shows microglial cells with typical bipolar morphology. (B) Shows a higher magnification of cells in (A), demonstrating both bipolar (flat arrow head) and apolar cells (arrow). Magnifications (A) $\times 125$; (B) $\times 250$. 
intensity of staining is given in Table 1), 4-7 days after enrichment. The surface immunostaining for MHC class II was comparatively weaker and was only detected on a minority of microglial cells (less than $50 \%$ ). Further, the cultured microglial cells did not stain with antibodies to GFAP, O4, galactocerebroside, or fibronectin, markers for astrocytes, oligodendrocytes and fibroblasts, respectively (Table 1). Interestingly, surface antigen staining on adherent cells was similar in all cases and was most intense on the cell body and at the distal end of the elongated cell processes (Figures 2 and 3$)$.

Effect of L-methyl ester treatment on cultured cells L-methyl ester (LME) is a potent toxin for cells of the monocyte/macrophage lineage (Thiele et al, 1985). Treatment of the cell cultures with LME

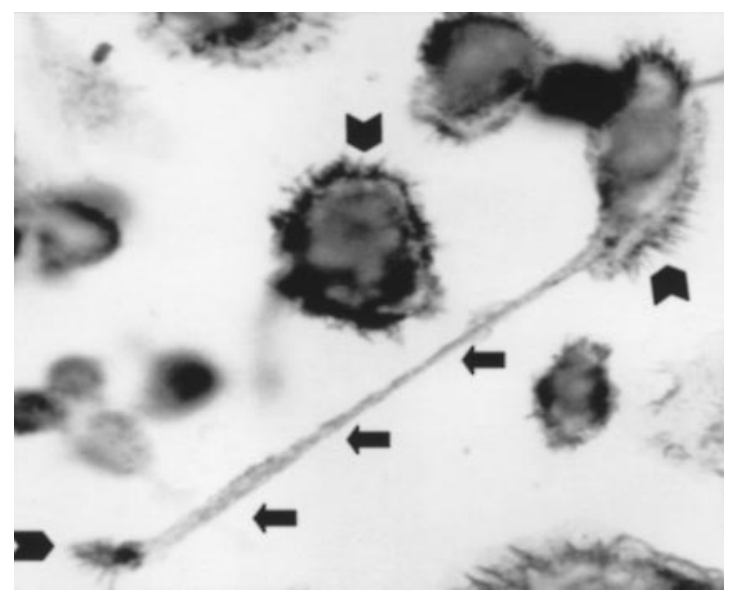

Figure 2 Cell surface staining for CD14 on cultured ovine microglial cells. Highly enriched microglial cells were immunostained for cell surface expression of antigens common to cells of the monocyte/macrophage lineage. Cells were stained 4-7 days after enrichment. Staining was localised to the cell membrane of the cell body and the tip of elongated processes (arrowhead). Note lack of staining of long processes (arrows). Magnification $\times 300$.

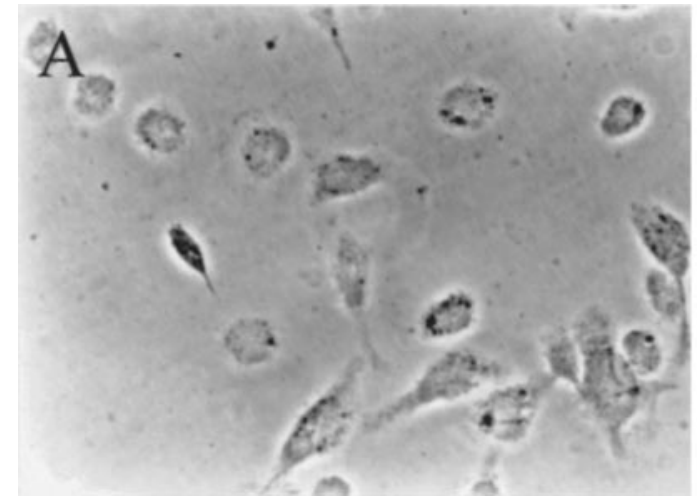

resulted in cytotoxicity. The initial toxic effects of LME were apparent within 30 min of treatment in the form of cytoplasmic ballooning (Figure 4). Prolonged LME treatment resulted in loss of these cells. In contrast, LME treatment did not have any detrimental effects on astrocytes and other cells in mixed glial cultures.

Taken together the morphology, the cell surface phenotype and the sensitivity to LME confirm that the cultures established were highly enriched for ovine microglial cells.

\section{Infection of microglial cells with $M V V$}

To assess the tropism of MVV for these ovine microglial cells, cultures were infected with the K1514 strain of MVV on day five post-enrichment. Uninfected cultures were used as controls for immunostaining and cytokine RT-PCR assays. The earliest cellular changes were first apparent by light microscopy at $2-3$ days post-infection, as an increase in cytoplasmic vacuoles/vesicles. By day five post-infection, the cell membrane appeared discontinuous and irregular, and by days $8-9$ the

Table 1 Immunocytochemical reactivity of cultured ovine microglial cells

\begin{tabular}{llc}
\hline Antibody & Specificity & Microglia \\
\hline SBUT-6 & CD1 & +++ \\
VPM19 & MHC-I & +++ \\
VPM36 & MHC-II DR & + \\
VPM54 & MHC-II DQ & + \\
LFA-1 & CD11a & +++ \\
OM1 & CD11c & +++ \\
VPM65 & CD14 & +++ \\
${ }^{\mathrm{a}}$ GSI-B4 & ${ }^{\mathrm{b}} \beta$-NacGal & +++ \\
${ }^{\mathrm{C}}$ Anti-O4 & Oligodendroctyes & - \\
${ }^{\mathrm{c}}$ Anti-Galc & Oligodendrocytes & - \\
${ }^{\mathrm{c}}$ Anti-GFAP & Astrocytes & - \\
\hline
\end{tabular}

Enriched microglial cells were immunostained at 7-10 days post-culture. $(+++)$ indicates strong, $(+)$ indicates weak and $(-)$ indicates no staining above background levels, respectively. ${ }^{\mathrm{a}} \beta$ $\mathrm{N}$-acetyl galactose; ${ }^{b}$ lectin; ${ }^{\mathrm{c}}$ cross reacts with ovine tissues.

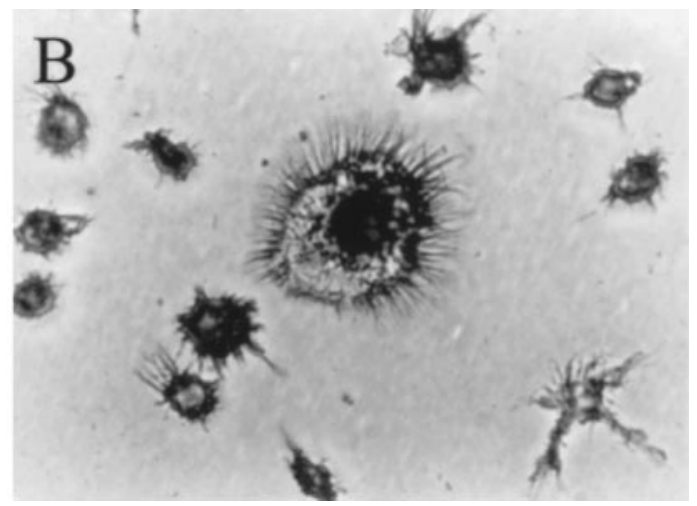

Figure 3 Cultured ovine microglial cells express surface CD1. Highly enriched microglial cultures were stained for the expression of CD1 on 4-7 days after enrichment. (A) The negative control where cultures were stained with an isotype control antibody. Cells in (B) were stained with anti-CD1 antibody. Note the surface staining of CD1 and localisation of CD antigens on membrane spike. Magnifications: (A) $\times 125$; (B) $\times 250$. 


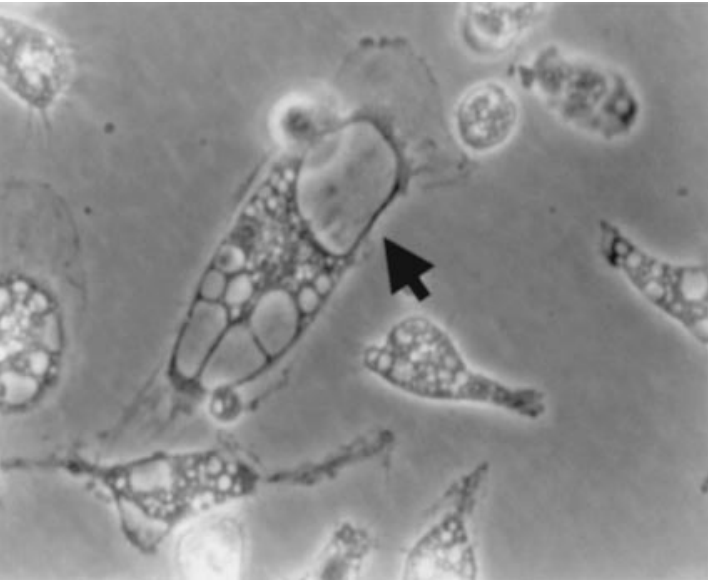

Figure 4 L-methyl ester is toxic to cultured microglial cells. Microglial cultures were treated with this lysosomo-tropic agent (7.5 $\mathrm{mM}$ in serum-free DME) and morphological changes were followed by light microscopy. The initial sign of toxicity was intracellular ballooning was apparent within $30 \mathrm{~min}$ of LME treatment (arrowhead). LME treatment resulted in eventual loss of cells from culture. Magnification $\times 250$.

cell membrane had shrunk extensively with cells becoming detached from the monolayer. By day 4 post-infection, the majority of cells in the culture stained positive with a monoclonal antibody against the major viral core protein p25. In infected cultures, p25 staining was punctate and always localized to the cytoplasm (Figure 5). Multinucleated giant cells were observed only rarely in infected cultures. Infectious virus was detectable in the supernatants of infected cultures within $48 \mathrm{~h}$ and increased with time (Figure 6).

\section{Effect of MVV infection on microglial-derived cytokines}

It has been suggested that microglial released cytokines are major contributors to the neuropathology in retroviral neuropathies (Baszler et al, 1994; Nuovo and Alfieri, 1996; Sopper et al, 1996; Craig et al, 1997). To investigate this, changes in cytokine gene expression in infected ovine microglial cells were investigated. Semi-quantitative RT - PCR analyses of cytokine transcripts were carried out by comparison of PCR cycle numbers, determined empirically, against an internal control gene, ATPase. Infection of cultured microglial cells with MVV resulted in increased expression of $\mathrm{TNF} \alpha$ and IL-6 (Figure 7). TGF $\beta$-1 transcripts were present at relatively high levels in both control and MVVinfected cultures, and there was no statistical difference in transcript levels (Figure 7). No transcripts were detected for IL-1 $\beta$, GM-CSF, IL-10, or IL12 in control or infected cells. To test whether these PCR assays could potentially amplify their intended brain-derived transcripts, we tested these assays on a brain material derived from a sheep with a nonspecified mononuclear cell inflammatory response. Most cytokines were detected from the brain of this

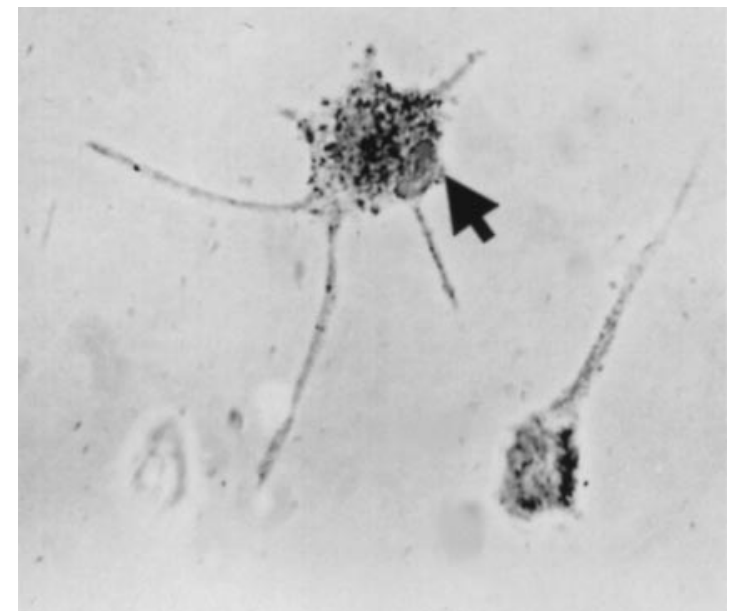

Figure 5 Immunostaining for viral p25 in MVV-infected microglial cells. Microglial cultures infected with MVV and were immunostained on days 4-7 post-infection with a monoclonal antibody against the major viral core protein (p25). Note punctate cytoplasmic staining of p25 in infected cells. The arrow indicates the location of the nucleus. Magnification $\times 300$.

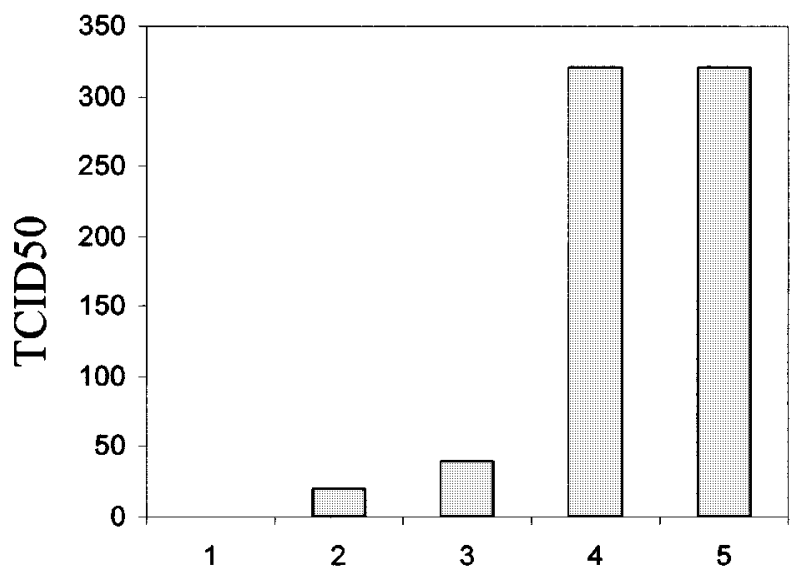

\section{Days post-infection}

Figure 6 Productive infection of microglial cultures with MVV. Enriched microglial cells (100000 per $35 \mathrm{~mm}$ plate) were infected with $100 \mathrm{TCID}_{50}$ of MVV. Supernatants from infected cultures were harvested at different time points post-infection and titred on sheep fibroblasts for infectious virus.

sheep (Figure 8). Therefore, the PCR assays could potentially amplify their intended targets.

\section{Discussion}

Techniques for the preparation of highly enriched cultures of ovine microglia were established. These cells were characterised as microglial cells by their morphology, cell surface phenotype and sensitivity to LME treatment. Similar immunostaining patterns and morphological features have been observed with microglial cells from other species (Akiyama and 
A
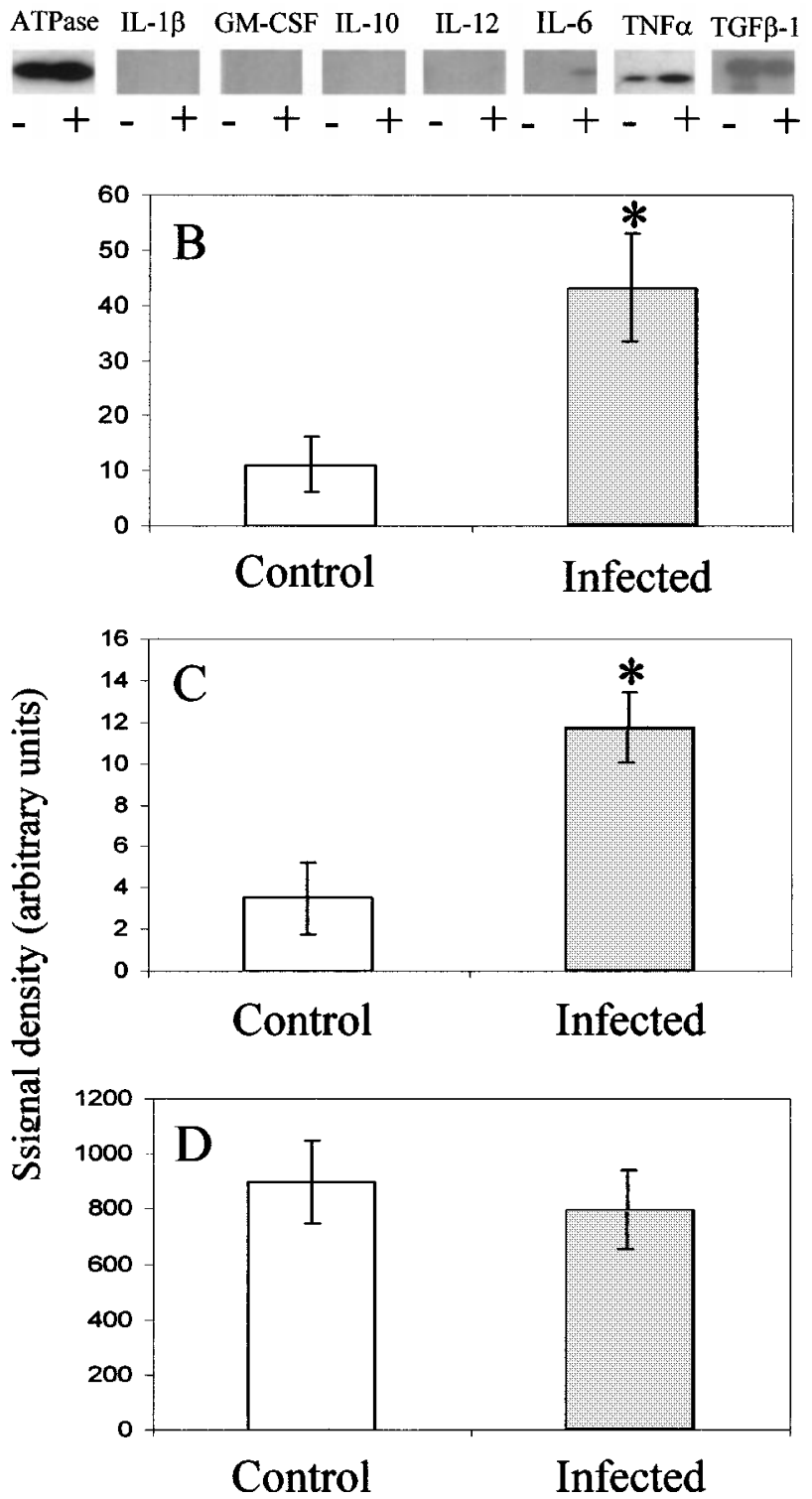

Figure 7 Effect of MVV infection on mRNA expression of microglial-derived cytokines. Enriched microglial cell cultures were either mock-infected (control) or MVV-infected. Total RNA was harvested from cultures on day 4 post-infection, DNase-Itreated and then reverse-transcribed and used for amplification of cytokine transcripts and the housekeeping gene ATPase. PCR products were resolved by gel electrophoresis and blotted. The Southern blots were probed with gene-specific internal primers and resultant signals scanned, and normalised against the signal for the ATPase transcript. (A) is a representative Southern blot, where $(-)$ and (+) correspond to mock-infected and MVV-infected microglial cultures, respectively. (B), (C) and (D) are the mean$\mathrm{s} \pm$ one standard deviation compiled from four separate experiments, and refer to $\mathrm{TNF} \alpha$, IL-6, and $\mathrm{TGF} \beta-1$, respectively. A significant increase $\left(P<0.05,{ }^{*}\right)$ was observed in the expression of TNF $\alpha$ and IL-6 in MVV-infected cultures compared to control cultures. In contrast, no significant change was observed in the expression of TGF $\beta$-1 between control and infected cultures.

McGeer, 1990; Colton et al, 1992; Baszler et al, 1994; Ford et al, 1995; Becher and Antel, 1996; Havenith

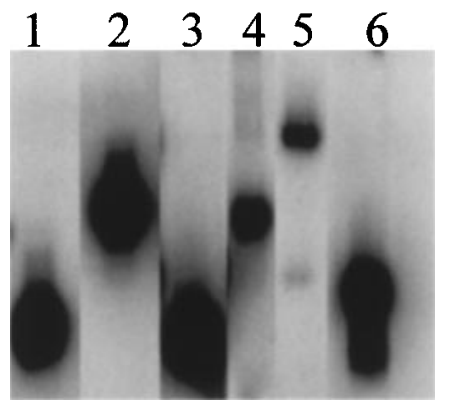

Figure 8 Detection of brain-derived ovine cytokines using genespecific PCRs. Total cellular RNA isolated from the brain of a sheep known to contain inflammatory infiltrates by histology was used to test the specificity and sensitivity of the PCR assays. PCR products were resolved by gel electrophoresis and blotted. The Southern blots were probed with gene-specific internal primers. The figure is the autoradiograph of the probed blots. 1: ATPase (168 bp); 2: IL-1 $\beta$ (466 bp); 3: TNF $\alpha$ (144 bp); 4: IL-10 (452 bp) 5: IL-6 (622 bp); and 6: TGF $\beta-1$ (336 bp)

et al, 1998). The enriched ovine microglial cultures were used to study infection with MVV.

To our knowledge, this if the first study to demonstrate the presence of CD1 on microglial cells from any species. The CD1 family of cell surface glycoproteins are expressed on most antigen presenting cells and have been shown to present non-protein antigens to the immune system (reviewed by Porcelli, 1995). At present, it is not clear what role, if any, microglial CD1 may play in the CNS environment in general or in MVV infection specifically. Expression of MHC was detected on cultured ovine microglial cells, with MHC-class I staining more prominent than MHC-class II staining. This is consistent with previous in vivo studies in which ovine parenchymal microglial cells were shown to express both MHCclass I and class II molecules (Torsteinsdottir et al, 1994; Bergsteinsdottir et al, 1998).

The punctate pattern of viral p25 immunostaining in infected microglial cultures demonstrates that MVV infects and replicates in cultured ovine microglial cells. This pattern of punctate p25 immunostaining is consistently observed in cells of the monocyte/macrophage lineage infected with MVV. Both alveolar macrophages and blood monocytederived macrophages, but not fibroblasts, show similar immunostaining patterns (Lee et al, 1996). The infection of microglial cells was productive since culture supernatants contained infectious virions. Together, these findings demonstrate not only that microglial cells can become infected with the virus, but also that the packaging and egress pathways for the progeny virions are intact in these cells.

Cytokine production has been closely linked with lentiviral infections of cells of the monocyte/ macrophage lineage and has been suggested to contribute to the CNS pathology (Baszler et al, 1994; Nuovo and Alfieri, 1996; Sopper et al, 1996; Craig et al, 1997). The profile of cytokines produced in MVV-infected primary ovine microglial cells 
under our experimental conditions demonstrated a restricted pattern of gene expression. This restriction at the transcriptional level is more stringent than that observed with other tissue macrophages. For example, infection of freshly isolated ovine blood monocyte-derived macrophages with MVV resulted in up-regulation of mRNA for IL- $1 \beta$, TNF $\alpha$, IL-6, and IL-10 (Z Zhang and G Harkiss, personal communication). This restricted cytokine output from microglial cells could be appropriate to the CNS environment, which is an immunologically specialised site. In support of this notion, cultured ovine microglial cells constitutively expressed high levels of TGF $\beta-1$ mRNA, a cytokine with potent immunoinhibitory effects (reviewed by Bogden and Nathan, 1993). Infected microglial cells produced mRNA for the pro-inflammatory cytokines TNF $\alpha$ and IL-6. This is consistent with a previous study in which $\mathrm{TNF} \alpha$ immunoreactivity in MVV-infected brain tissues was demonstrated to associate with brain macrophages (Craig et al, 1997). Intrathecal expression of $\mathrm{TNF} \alpha$ has also been demonstrated in primate lentivirus infections (Nuovo and Alfieri, 1996; Sopper et al, 1996). Increased transcription of IL-6 mRNA has also been reported in caprine microglial cultures infected with CAEV (Baszler et $a l, 1994)$ and in the brains of SIV-infected macaques (Sopper et al, 1996). Over-expression of IL-6 in the murine CNS has been shown to result in reactive astrocytosis and an increase in ramified microglial cells (Fattori et al, 1995). Interestingly, inoculation of HIV-1-infected monocytes into the brains of severe combined immunodeficient mice resulted in microgliosis. These activated microglial cells produced IL-6 (Persisky et al, 1996). These in vitro studies demonstrate that MVV can productively infect ovine microglial cells resulting in transcription of proinflammatory cytokine genes. These results are consistent with the hypothesis that in sheep brain direct infection of microglial cells by MVV results in production of pro-inflammatory cytokines which may be important mediators of neuropathology.

\section{Materials and methods}

\section{Primary ovine glial cultures}

Mixed breeds of British lambs (male and female and less than 1 week old) were used to set up cell cultures. The brain stem region was the source of glial cells. This region included diencephalon, metencephalon (excluding cerebellum), and myelencephalon (excluding cervical portion of spinal cord caudal to obex). After euthanasia with Euthatol the brain stem was removed and placed in Leibovitz L-15 medium (GibcoBRL), supplemented with benzylpenicillin $\quad(100 \mathrm{IU} / \mathrm{ml}), \quad$ streptomycin $(100 \mu \mathrm{g} / \mathrm{ml})$, and fungizone $(2.5 \mathrm{mg} / \mathrm{ml})$. The meninges and major blood vessels were removed. The tissue was cut into approximately 1-2 $\mathrm{mm}$ fragments and triturated using a $10 \mathrm{ml}$ glass pipette. The suspension was spun at 500 r.p.m. $(50 \times \mathrm{g})$ in a bench-top centrifuge for $1 \mathrm{~min}$ and the supernatant containing mixed glial cells was removed and kept. The cell pellet was re-suspended in $4 \mathrm{ml}$ of fresh L15 medium and the procedure repeated another three times. The supernatants from each cycle were pooled and centrifuged at 1000 r.p.m. $(150 \times$ g) for 3 min. The pellet containing glial cells was resuspended in $5 \mathrm{ml}$ of Dulbecco's minimum essential medium (DME) containing HEPES (10 mM), NaH$\mathrm{CO}_{3}(10 \mathrm{mM}), \quad 10 \%$ heat-inactivated foetal calf serum (FCS) and antibiotics (see above). The resuspended cells derived from one lamb brain were plated at high density in a T25 tissue culture flask (Nunc, Denmark), pre-treated with poly-D-lysine $(0.2 \mathrm{mg} / \mathrm{ml}$ for $30 \mathrm{~min}$, rinsed with sterile water and air-dried). The cells were cultured at $37^{\circ} \mathrm{C}$, at $5 \%$ $\mathrm{CO}_{2}$ in a humidified (95\%) atmosphere, and left undisturbed for 4 days. Due to the high density of cells, a large number of cells remained floating.

After 4 days of culture, the floating cells were removed and plated on $35 \mathrm{~mm}$ poly-D-lysine coated dishes for $15 \mathrm{~min}$ at $37^{\circ} \mathrm{C}$. The medium was then removed and the adhered cells rinsed once with serum-free DME and then cultured in DME plus $10 \%$ FCS. This short incubation step allowed the adherence of putative microglial cells without significant adherence of other glial cells or fibroblasts. After overnight culture, the FCS was reduced to $2 \%$ to reduce growth of any fibroblasts.

\section{Antibodies}

Monoclonal antibodies SBUT-6 (Hopkins and Dutia, 1991), VPM 65 (Gupta et al, 1996), LFA-1 (Gupta et al, 1995), IL-A15 and OM1 (Gupta et al, 1993) were derived from hybridoma supernatants and were used undiluted (Table 2). VPM65, LFA-1, ILA15, OM-1, VPM19, and VPM54 all are ovinespecific antibodies. SBUT-6 was raised against bovine CD1 and cross-reacts with ovine tissues. The monoclonal antibody $\mathrm{O} 4$ clone 81 (Boehringer Mannheim, Germany) and polyclonal anti-galactocerebroside (Sigma Chemical, UK) markers for immature and mature oligodendrocytes (Raff et al, 1978; Sommer and Schachner, 1981) were used at final dilutions of $1: 20$ and $1: 100$, respectively. The monoclonal antibody A2B5 (Boehringer Mannheim), a marker for cells of neuroglial origin (Eisenbarth et al, 1979) was used at a final dilution of $1: 10$. The biotin conjugated isolectin Griffonia simplicifolia GSI-B ${ }_{4}$ (Sigma Chemicals), a marker for brain microglial cells (Colton et al, 1992) was used at a final dilution of $1: 100$. Polyclonal rabbit anti-bovine glial fibrillary acidic protein (GFAP; Dako, UK), a marker for astroglial cells (Bignami et $a l, 1972$ ) was used at a final dilution of $1: 100$. The same dilution was used with rabbit anti-human 
fibronectin (Sigma Chemicals), for detection of fibroblasts. The antibodies against astrocytes, oligodendrocytes and fibroblasts were tested on ovine brain-derived cultures. These antibodies crossreacted with ovine tissues (data not shown).

\section{Indirect immunostaining}

Cells grown on $35 \mathrm{~mm}$ tissue culture dishes were used for immunostaining 7-10 days post-plating. For cell surface markers, live cells were first incubated with primary antibody, rinsed with phosphate-buffered saline (PBS), fixed with $4 \%$ (w/v) para-formaldehyde in PBS (PFA/PBS), followed by a blocking step with $3 \%(\mathrm{v} / \mathrm{v})$ normal goat serum (NGS) in PBS. Cells were then incubated with fluorescein or alkaline-phosphate-conjugated secondary antibody, diluted in 1\% NGS/PBS.

For immunostaining of intracellular antigens, cells were first fixed and then permeabilised with $0.3 \%(\mathrm{v} / \mathrm{v})$ Triton X-100 in PBS before incubation with primary antibody. Immunostaining of microglial cells with anti-CD markers was performed using goat-anti-mouse alkaline phosphatase conjugate as secondary antibody, with nitroblue tetrazolium and X-phosphate as detection system (Boehringer Mannheim). The negative control was normal mouse serum as primary antibody in place of immune serum. Presence of virus in microglial cells was detected using a monoclonal antibody against the viral p25 major core protein (Reyburn et al, 1992).

\section{Virus infection}

The neural adapted Icelandic K1514 strain of MVV was used (Staskus et al, 1991). One hundred thousand cells were infected with 100 TCID50 by incubation in serum-free DME for $2 \mathrm{~h}$ at $37^{\circ} \mathrm{C}$, followed by three rinses with serum-free DME and finally incubated in DME plus 2\% FCS.

\section{Virus titer determination}

Virus titers from infected cultures were determined using sheep fibroblasts as indicator cells. Fibroblasts were seeded in 96-well flat-bottomed plates at a density of $1 \times 10^{4}$ cells $/ \mathrm{ml}$ in DME plus $2 \%$ FCS. The medium was removed and serial dilutions of test samples were added to each well. Each dilution was tested in triplicate. Supernatants from mockinfected cultures were used as negative controls.
After incubation for 7 days, cells were fixed and stained with Giemsa's stain. The cytopathic effect was scored by the presence of syncytium and/or lysis. The tissue culture infectious dose $50\left(\mathrm{TCID}_{50}\right)$ was determined by the method of Reed and Muench (1938).

\section{Amplification of cytokine gene transcripts}

Total cellular RNA was isolated from mock-infected and virus-infected microglial cultures on day four post-infection. Briefly, RNA lysis buffer (Qiagen) was added to cells on the day of harvest and total RNA extracted using RNeasy columns (Qiagen) according to manufacturer's instructions. To eliminate possible contaminating genomic DNA, the isolated RNA samples were pre-treated with DNAse-I (RNAse-free, Pharmacia Biotech), before reverse transcription. The DNAse-treated samples were then reverse transcribed with SuperScript II (GibcoBRL).

Amplification of microglial-derived cytokine genes and the housekeeping gene ATPase was carried out using ovine gene-specific intron-spanning RT-PCR assays (Table 2) (Dutia et al, 1994; Ebrahimi et al, 1995; Woodall et al, 1997). All PCR reactions were performed using a denaturing step at $95^{\circ} \mathrm{C}$ for $1 \mathrm{~min}$, an annealing temperature at $55^{\circ} \mathrm{C}$ for $1 \mathrm{~min}$, and an extension step at $72^{\circ} \mathrm{C}$ for $2 \mathrm{~min}$, with an extension step at $72^{\circ} \mathrm{C}$ for 5 min was introduced to allow for the completion of DNA strand synthesis. PCR reactions were performed in $2 \mathrm{mM} \mathrm{MgCl}_{2}$ for amplification of all cytokine transcripts and in $3.5 \mathrm{mM} \mathrm{MgCl}{ }_{2}$ for amplification of ATPase transcripts.

The ubiquitous ovine housekeeping gene alpha sub-unit of the ATPase $(\mathrm{Na}+/ \mathrm{K}+)$ pump was used as the internal control for cytokine PCR reactions (Woodall et al, 1994).

PCR products were resolved by running $20 \mu \mathrm{l}$ aliquots from PCR reactions on $1.6 \%(\mathrm{w} / \mathrm{v})$ agarose gels. Southern blots were performed on resolved PCR products with ${ }^{32} \mathrm{P}-3$ '-end-labelled probes with high specific activities. The gene-specific signal intensities were determined using the ImageQuaNT ${ }^{\infty}$ phosphorimage analyzer (Molecular Dynamics, UK). The definition of pixel intensity, as given in the ImageQuaNT ${ }^{\infty}$ user's guide is 'the intensity, which reflects signal strength. The pixel

Table 2 PCR Primers and internal probe sequences for ovine cytokines and the housekeeping gene ATPase

\begin{tabular}{llll}
\hline Gene & Forward primer & Reverse primer & Internal probe \\
\hline IL-1 $\beta$ & TACGAACATGTCTTCCG & CCAGTTAGGGTACAGGA & CGATGAGCTTCTGTGTGATGCAGC \\
TNF $\alpha$ & ATGAGCACCAAAACATGATC & GAAGAGCGTGGTGGCTCC & AGGAGGTCTCTCCAACAAAGCA \\
TGF $\beta-1$ & GCCCTGGACACCAACTACTG & TCAGCTGCACTTGCAGGAG & CCTTCCGGAAGTCAATGTAGAGCTG \\
IL-6 & ATGAACTCCCTCTTCACAAGCG & ACTTCATCCGAATAGCTCTC & AAATGACACCACCCCAAGC \\
GM-CSF & AGTCCTCAACAGGATGTGC & CGTCTGTGAGGTAAGCTT & AACGACAGCACTGACACTGCTGCTGTG \\
IL-10 & ATGCCACAGGTGAGAC & TTCACAGAGAAGCTCAG & ACCTGCTCCACCGCCTTG \\
IL-12 & AGATGCTGGGCAGTACACCT & CAATGGGCAGGCTCTCCTC & GCTCGTGGCTGACAGCAATCATGACT \\
ATPase & GCTGACTTGGTCATCTGC & CAGGTAGGTTTGAGGGGATAC & CATCCCCTGCTGGAAGACGGAATT \\
\end{tabular}


intensity units depend on which instrument was used to collect the image and in the case of a phosphorImager, the unit is counts.'

The normalisation of cytokine PCR signals were carried out according to previously published protocols (Woodall et al, 1997). Briefly, PCR cycle numbers that produced subsaturation levels of amplified products (31 cycles for ATPase and all cytokines except TGF $\beta$-1, and 29 cycles for TGF $\beta$-1) were determined empirically by performing PCR for each assay on mixed cDNA samples. The results from each cytokine assay were then normalised against the reading for the housekeeping gene ATPase.

Ovine cytokine genes cloned in plasmid vectors were used to test for specificity of PCR assays (data not shown). Furthermore, to test the sensitivity of the PCR assays on RNA isolated from brain tissues,

\section{References}

Akiyama H, McGeer P (1990). Brain microglia constitutively express beta-2 integrins. J Neuroimmunol 30: 81.

Baszler T, Harwood W, Lester K, Davis W, Knowles D (1994). Characterization of caprine microglial cells and in vitro infection with caprine arthritis-encephalitis lentivirus. Lab Invest 70: 933.

Becher B, Antel J (1996). Comparison of phenotypic and functional properties of immediately ex vivo and cultured human adult microglia. Glia 18: 1.

Bergsteinsdottir K, Arnadottir S, Torsteinsdottir S, Agnarsdottir G, Andresdottir V, Pettursson G, Georgsson $G$ (1998). Constitutive and visna virus induced expression of class I and II major histocompatibility complex antigens in the central nervous system of sheep and their role in the pathogenesis of visna lesions. Neuropathol Appl Neurobiol 24: 224-232.

Bignami A, Eng LF, Dahl D, Uyeda CT (1972). Localization of the glial fibrillary acidic protein in astrocytes by immunofluorescence. Brain Res 43: $429-435$.

Bogdan C, Nathan C (1993). Modulation of macrophage function by transforming growth factor beta, interleukin-4, and interleukin-10. Ann NY Acad Sci 685: $713-739$.

Brinkmann R, Schwinn A, Muller J, Stahl-Hennig C, Coulibaly C, Hunsmann G, Czub S, Rethwilm A, Dorries R, ter Meulen V (1993). In vitro and in vivo infection of rhesus monkey microglial cells by simian immunodeficiency virus. Virology 195: $561-568$.

Budka H (1989). Human immunodeficiency virus (HIV)induced disease of the central nervous system: pathology and implications for pathogenesis. Acta Neuropathol 77: 225-236.

Colton CA, Abel C, Patchett J, Keri J, Yao J (1992). Lectin staining of cultured CNS microglia. J Histochem Cytochem 40: 505-512.

Craig LE, Sheffer D, Meyer AL, Hauer D, Lechner F, Peterhans E, Adams RJ, Clements JE, Narayan O, Zink MC (1997). Pathogenesis of ovine lentiviral encephalitis: derivation of a neurovirulent strain by in vivo passage. J Neurovirol 3: 417-427.

Dow S, Poss M, Hoover E (1990). Feline immunodeficiency virus: a neurotropic lentivirus. J AIDS 3: 658. expected to be at comparatively minute quantities, total RNA was isolated from an ovine brain known to contain inflammatory infiltrates by histology. This material was then used in the PCR assays (Figure 8). The results from these PCRs showed that these assays could amplify their intended targets and that the methodology worked.

\section{Acknowledgements}

We are grateful to Drs Bernadette Dutia and Chris Woodall for providing primer sequences for PCR assays. We also acknowledge the excellent technical assistance of Alison Baker and Jim Williams (Moredun Research Institute, Edinburgh).

Dutia BM, Hunt P, Sargan DR, Dalziel RG, Hopkins J (1994). Sequence of the sheep interleukin10-encoding cDNA. Gene 149: 393-394.

Ebrahimi B, Roy DJ, Bird P, Sargan DR (1995). Cloning, sequencing and expression of the ovine interleukin 6 gene. Cytokine 7: 232-236.

Eisenbarth GS, Walsh FS, Nirenberg M (1979). Monoclonal antibody to a plasma membrane antigen of neurons. Proc Natl Acad Sci USA 76: 4913-4917.

Fattori E, Lazzaro D, Musiani P, Modesti A, Alonzi T, Ciliberto G (1995). IL-6 expression in neurons of transgenic mice causes reactive astrocytosis and increase in ramified microglial cells but no neuronal damage. Eur J Neurosci 7: 2441-2449.

Ford A, Goodsall A, Hickey W, Sedgwick J (1995). Normal adult ramified microglia separated from other central nervous system macrophages by flow cytometric sorting. Phenotypic differences defined and direct ex vivo antigen presentation to myelin basic protein-reactive CD4+ $\mathrm{T}$ cells compared. J Immunol 154: 4309.

Gabuzda DH, Ho DD, de la Monte SM, Hirsch MS, Rota TR, Sobel RA (1986). Immunohistochemical identification of HTLV-III antigen in brains of patients with AIDS. Ann Neurol 20: 289-295.

Gendelman HE, Lipton SA, Tardiue M, Bukrinsky MI, Nottet HS (1994). The neuropathogenesis of HIV-1 infection [see comments]. J Leukoc Biol 56: 389-398.

Genis P, Jett M, Bernton EW, Boyle T, Gelbard HA, Dzenko K, Keane RW, Resnick L, Mizrachi Y, Volsky DJ, et al (1992). Cytokines and arachidonic metabolites produced during human immunodeficiency virus (HIV)-infected macrophage-astroglia interactions: implications for the neuropathogenesis of HIV disease. $J$ Exp Med 176: 1703-1718.

Georgsson G, Houwers D, Palsson P, Petursson G (1989). Expression of viral antigens in the central nervous system of visna-infected sheep: an immunohistochemical study on experimental visna induced by virus strains of increased neurovirulence. Acta Neuropathol 77: 299.

Georgsson G (1994). Neuropathologic aspects of lentiviral infections. Ann NY Acad Sci 724: 50. 
Giulian D, Li J, Bartel S, Broker J, Li X, Kirkpatrick JB (1995). Cell surface morphology identifies microglia as a distinct class of mononuclear phagocyte. J Neurosci 15: $7712-7726$.

Gupta VK, McConnell I, Hopkins J (1993). Reactivity of the CD11/CD18 workshop monoclonal antibodies in the sheep. Vet Immunol Immunopathol 39: 93-102.

Gupta VK, McConnell I, Pepin M, Davis WC, Dalziel RG, Hopkins J (1995). Biochemical and phenotypic characterization of the ovine beta 2 (leucocyte) integrins. J Comp Pathol 112: 339-349.

Gupta VK, McConnell I, Dalziel RG, Hopkins J (1996). Identification of the sheep homologue of the monocyte cell surface molecule-CD14. Vet Immunol Immunopathol 51: 89-99.

Havenith CE, Askew D, Walker WS (1998). Mouse resident microglia: isolation and characterization of immunoregulatory properties with naive CD4+ and CD8+ T-cells. Glia 22: 348-359.

Hopkins J, Dutia BM (1991). Workshop studies on the ovine CD1 homologue. Vet Immunol Immunopathol 27: $97-99$.

Koka P, He K, Zack JA, Kitchen S, Peacock W, Fried I, Tran T, Yashar SS, Merrill JE (1995). Human immunodeficiency virus 1 envelope proteins induce interleukin 1, tumor necrosis factor alpha, and nitric oxide in glial cultures derived from fetal, neonatal, and adult human brain. J Exp Med 182: 941-951.

Kure K, Llena JF, Lyman WD, Soeiro R, Weidenheim KM, Hirano A, Dickson DW (1991). Human immunodeficiency virus-1 infection of the nervous system: an autopsy study of 268 adult, pediatric, and fetal brains. Hum Pathol 22: $700-710$.

Lackner A, Smith M, Munn R, Martfeld D, Gardner M, Marx P, Dandekar S (1991). Localization of simian immunodeficiency virus in the central nervous system of rhesus monkeys. Am J Pathol 139: 609.

Lane TE, Buchmeier MJ, Watry DD, Fox HS (1996). Expression of inflammatory cytokines and inducible nitric oxide synthase in brains of SIV-infected rhesus monkeys: applications to HIV-induced central nervous system disease. Mol Med 2: 27-37.

Lee W, McConnell I, Blacklaws B (1996). Electron microscope studies of the replication of a British isolate of maedi visna virus in macrophages and skin cell lines. Vet Microbiol 49: 293.

Nathanson N, Panitch H, Palsson P, Petursson G, Georgsson G (1976). Pathogenesis of visna. II. Effect of immunosuppression upon early central nervous system lesions. Lab Invest 35: 444.

Nuovo G, Alfieri M (1996). AIDS dementia is associated with massive activated HIV-1 infection and concomitant expression of several cytokines. Mol Med 2: 358.

Palsson P (1974). Slow virus diseases of animals and man. Edited by R. Kimberlin. New York: NorthHoland/American Elsevier.

Persidsky Y, Limoges J, McComb R, et al. (1996) Human immunodeficiency virus encephalitis in SCID mice. Am J Pathol 149: 1027.

Petursson G, Nathanson N, Georgsson G, Panitch H, Palsson PA (1976). Pathogenesis of visna. I. Sequential virologic, serologic, and pathologic studies. Lab Invest 35: $402-412$.
Philippon V, Vellutini C, Gambarelli D, Harkiss G, Arbuthnott G, Metzger D, Roubin R, Filippi P (1994). The basic domain of the lentiviral Tat protein is responsible for damages in mouse brain: involvement of cytokines. Virology 205: 519-529.

Porcelli S (1995). The CD1 family: a third lineage of antigen-presenting molecules. Adv Immunol 59: 1.

Raff MC, Abney E, Brockes JP, Hornby-Smith A (1978). Schwann cell growth factors. Cell 15: 813-822.

Reed L, Muench H (1938). A simple method of estimating fifty percent end-points. Am J Hygiene 24: 493.

Reyburn HT, Roy DJ, Blacklaws BA, Sargan DR, McConnell I (1992). Expression of maedi-visna virus major core protein, p25: development of a sensitive p25 antigen detection assay. J Virol Methods 37: 305-320.

Sommer I, Schachner M (1981). Monoclonal antibodies (O1 to O4) to oligodendrocyte cell surfaces: an immunocytological study in the central nervous system. Dev Biol 83: 311-327.

Sopper S, Demuth M, Stahl-Hennig C, Hunsmann G, Plesker R, Coulibaly C, Czub S, Ceska M, Koutsilieri E, Riederer P, Brinkmann R, Katz M, ter Meulen V (1996). The effect of simian immunodeficiency virus infection in vitro and in vivo on the cytokine production of isolated microglia and peripheral macrophages from rhesus monkey. Virology 220: 320-329.

Staskus KA, Retzel EF, Lewis ED, Silsby JL, St Cyr S, Rank JM, Wietgrefe SW, Haase AT, Cook R, Fast D, Geiser PT, Harty JT, Kong SH, Lahti CJ, Neufeld TP, Porter TE, Shoop E, Zachow KR (1991). Isolation of replication-competent molecular clones of visna virus. Virology 181: $228-240$.

Thiele DL, Lipsky PE (1985). Regulation of cellular function by products of lysosomal enzyme activity: elimination of human natural killer cells by a dipeptide methyl ester generated from L-leucine methyl ester by monocytes or polymorphonuclear leukocytes. Proc Natl Acad Sci USA 82: 2468-2472.

Torsteinsdottir S, Georgsson G, Gisladottir E, Rafnar B, Palsson P, Petursson G (1992). Pathogenesis of central nervous system lesions in visna: cell-mediated immunity and lymphocyte subsets in blood, brain and cerebrospinal fluid. J Neuroimmunol 41: 149.

Torsteinsdottir S, Georgsson G, Gisladottir E, Rafnar B, Palsson P, Petursson G (1994). Pathogenesis of central nervous system lesions in visna cell-mediated immunity and lymphocyte subsets in blood, brain, and cerebrospinal fluid. Ann NY Acad Sci 724: 159.

Wiley CA, Schrier RD, Nelson JA, Lampert PW, Oldstone MB (1986). Cellular localization of human immunodeficiency virus infection within the brains of acquired immune deficiency syndrome patients. Proc Natl Acad Sci USA 83: 7089-7093.

Woodall C, Mylne J, McKelvie W, Watt N (1994). A technique for the sequential isolation of RNA and DNA from embryos for screening for viruses. $J$ Virol Methods 46: 263.

Woodall CJ, Maclaren LJ, Watt NJ (1997). Differential levels of mRNA for cytokines, the interleukin-2 receptor and class II DR/DQ genes in ovine interstitial pneumonia induced by maedi-visna virus infection. Vet Pathology 34: 204-211. 